\title{
La revolución entra a la escuela. Recuerdos, imágenes y vivencias de la educación socialista en México
}

\author{
Revolution in the Schools. \\ Memories, Images and Experiences \\ of Socialist Education in Mexico
}

\author{
María Concepción Martínez Omaña \\ Instituto de Investigaciones Dr. José María Luis Mora \\ cmartinez@mora.edu.mx
}

\begin{abstract}
Resumen
En este texto se recuperan las experiencias registradas en la memoria individual acerca de las ideas, los modelos y las prácticas educativas desarrolladas en el periodo cardenista, con base en el testimonio oral de un ex alumno de la escuela primaria Benito Juárez, una de las primeras instituciones que adoptaron la educación socialista en San Martín Texmelucan, en el estado de Puebla. El trabajo pretende dar a conocer los alcances de la educación socialista en los hábitos escolares, los cambios que generó la co-educación en la configuración de los espacios y tiempos escolares y en la convivencia social, así como en la vida cotidiana escolar en su conjunto. Se aborda también la actitud y comportamiento de los padres de familia y maestros ante esta política educativa.
\end{abstract}

Palabras clave: memoria, historia oral, educación socialista.

\section{Abstract}

Based on the oral testimony of a former student at the primary school 'Benito Juárez' in San Martín Texmelucan, state of Puebla (one of the first institutions to adopt socialist education), this article recovers an individual's experience of educational ideals, models and practices during the Cárdenas administration (1934-1940) as registered in his memory. The study focuses on the changes introduced in schoolchildren's habits, in particular the impact of co-education on the configuration of the 
school's space and time, everyday interactions and school life in general. The attitudes and actions of parents and teachers towards the new policies are also examined.

Keywords: memory, oral history, socialist education.

\section{Introducción}

Uno de los aspectos más emblemáticos de la construcción del Estado posrevolucionario mexicano fue el impulso a la educación, en especial la educación primaria rural. Las elites políticas y culturales la concibieron como una de las herramientas más importantes para alcanzar una sociedad más justa, libre y equitativa. En este marco, la política educativa impulsada durante la administración cardenista tuvo un carácter profundamente reformador al pretender una transformación de las ideas, los fines, los modelos y las prácticas pedagógicas mediante el diseño y el impulso de la política educativa que se sintetizó y definió como educación socialista. Dicha educación introdujo dos elementos que, si bien habían estado presentes en algunas regiones del país, se convirtieron en el eje de la política del Ejecutivo federal: la coeducación y la educación sexual. ${ }^{1}$

En este texto, por medio de la historia oral, se pretende recuperar tanto las experiencias como los recuerdos y las imágenes de la primera generación de niños y niñas que asistieron a la escuela bajo dicha política educativa. Con base en el testimonio oral de uno de los alumnos de la escuela primaria Benito Juárez, ubicada en la ciudad de San Martín Texmelucan, estado de Puebla, se recrean los recuerdos de una persona que vivió la reforma educativa con la que se aplicaron los postulados de la escuela primaria denominada "socialista". Mediante el testimonio se reconstruye la memoria social e individual en torno a las ideas, los modelos, las prácticas educativas que contenía dicha educación. ¿Hasta dónde tal reforma modificó los hábitos escolares? ¿Qué tanto las relaciones entre los géneros y la convivencia

\footnotetext{
${ }^{1}$ En el campo de la historia de la educación en México se realizaron estudios sobre la educación socialista, que instrumentó el gobierno de Lázaro Cárdenas a nivel nacional entre los años 1934-1940. Entre el grupo de estudios destacan los que la analizan como política educativa a una escala nacional, destacando diferentes aspectos como el magisterio que la llevó a la práctica, los libros de texto, así como la infraestructura educativa. (Cruz, 1955; Quintanilla, 1999, Vázquez, 2000; Montes de Oca, 2007; Vaughan, 2001; Civera, 2006).) A partir de estos estudios pioneros siguió el interés entre los investigadores por estudiar los alcances de la educación socialista en las diversas regiones y estados de la república mexicana. Como suele suceder con otras políticas públicas que se diseñan a nivel federal, la instrumentación de dicha política educativa no ocurrió simultáneamente en todos los lugares; al contrario, sus alcances asumieron ritmos diferentes, impactando de distintas maneras a centros escolares, programas de estudio, magisterio, sociedad local con fuerte impacto entre los padres de familia, etcétera. Así, destacan las investigaciones sobre los estados de Aguascalientes (Rangel y Camacho, 1997), Jalisco (Yankelevich, 1999; Estado de México (Civera, 1999, Montes de Oca, 1999 y 2002, Palacios, 2006); Puebla, Sonora (Cruz, 1955, Vaughan, 1999 y 2001), Tlaxcala (Rockwell, 1999), La Laguna (Valdés, 1999), Morelos (Padilla, 2010); Oaxaca (Bertely, 2005), Sinaloa (Cueva, 1990), Territorio norte de Baja California (Maríñez, 2005).
} 
social cambiaron? ¿Cómo se reorganizaron los espacios y los tiempos escolares, la vida cotidiana escolar en su conjunto? ¿Qué representaron para niños y niñas? ¿Cuál fue la actitud y los comportamientos de los padres de familia y de los maestros ante esta política educativa? Estas son las preguntas que pretendemos responder en los tres apartados en los que organizamos este texto. ${ }^{2}$

En el primer apartado incluimos algunas notas metodológicas sobre el aporte de la historia oral al estudio y comprensión de procesos socio-históricos más amplios, como la reforma educativa en el periodo cardenista, desde la visión de los sujetos, protagonistas y testigos del acontecer contemporáneo. ${ }^{3}$

En el segundo apartado describimos el contexto social, entre otros aspectos el escenario local en donde se desenvuelve la infancia del protagonista y testigo de esta historia. En el último apartado analizamos la visión y experiencia de don Leandro adquirida en el transcurso de su educación primaria, vivencias que confrontamos con las características y postulados de la primaria socialista, que quedaron registradas tanto en los documentos de la época como en los estudios documentales y escritos de la política educativa cardenista. A través de esto, también podemos evaluar los alcances y significados de la reforma educativa.

\section{Aportes de la historia oral: la memoria, el relato de vida y los testimonios orales}

El estudio de los procesos sociales amplios como los que derivan de la política educativa que se implementó bajo el gobierno de Lázaro Cárdenas (1934-1940), en la década de los años treinta en el país, es posible realizarlo mediante la recuperación de la memoria social de pueblos y ciudades, así como la individual de sus habitantes, quienes fueron protagonistas, testigos y beneficiados de estas acciones públicas. La memoria la encontramos por varios caminos, uno de ellos a partir del diálogo y conversación que se desarrolla entre los sujetos que intervienen en una entrevista a profundidad "de historia oral": el entrevistado que relata su vida y el entrevistador (investigador), cuyo papel es de auxiliar al primero en el proceso de recordar. Por medio de la entrevista el investigador busca crear una evidencia histórica a través de la conversación con una persona cuya experiencia de vida es considerada memorable (Altamirano, 1994: 67).

\footnotetext{
${ }^{2}$ Los fragmentos del testimonio que presentamos en este texto se obtuvieron de la entrevista a don Leandro Padilla, realizada por Concepción Martínez y Antonio Padilla, en la ciudad de México, el 30 de enero de 2010

${ }^{3}$ Como Carmen Collado plantea, la historia oral es fundamental para escribir la historia contemporánea y, debido a su naturaleza, nos proporciona material distinto al que nos da el documento escrito, proporcionándonos las visiones particulares, las percepciones de los individuos sobre procesos históricos, con lo cual nos adentramos en su subjetividad y mentalidad (Collado, 1994: 31).
} 
La memoria se expresa en un discurso lingüístico y cobra materialidad en un relato de vida y en una narrativa particular, y de acuerdo con los atraídos por los estudios de procesos, acontecimientos y hechos contemporáneos -en suma, por la historia del tiempo presente-, constituye una dimensión y objeto de la historia. Uno de los rasgos distintivos de la memoria es que se apoya en la experiencia vivida, es eminentemente subjetiva y, por lo mismo, dinámica, cambiante. El proceso de memoria depende de la percepción del individuo, del orden en el que se aprende y vive algo, pero también si tiene interés en recordar. Con relación al primer aspecto, los entrevistados han experimentado los hechos y sus vivencias que recuerdan se ordenan en su mente no siempre acorde a la cronología colectiva, sino al grado de significación y aprendizaje. (Traverso, 2007: 73). En este sentido, la memoria queda asida a los hechos que han vivido los individuos, de los que han sido testigos, incluso actores, y a las impresiones que dichos acontecimientos han grabado en ellos. En el contexto de la entrevista, el entrevistador ayuda a construir la memoria y esto lo llevará a distinguir entre lo fáctico del recuerdo y la experiencia vivida (Altamirano, 1994: 67).

Como lo mencionamos líneas arriba, descubrimos que los recuerdos que se resguardan en la memoria de los individuos emergen en los relatos y narraciones de fragmentos de sus vidas. Como lo apunta Carlos Piña, la especificidad de los relatos, como el autobiográfico, es la de un discurso particular, de carácter interpretativo, y no la reconstrucción verbal de ciertos acontecimientos pasados. ¿Qué significa esto? Cuando se analizan las experiencias y vivencias narradas, los relatos se destacan por la calidad y cantidad específica de información histórica que proporcionan y, en este sentido, son útiles en un estudio de reconstrucción de ciertos sucesos históricos como el que nos ocupa en este texto, pero también hay que advertir, como lo menciona Piña, que cuando se relata o cuenta una vida, no se tiene la versión verbal de lo que la vida fue ni puede llegar a ser reflejo fiel, sino que es un discurso interpretativo -retazos de hechos dibujados por una perspectiva peculiar, selecciones, montajes, omisiones, atribuciones-, cuya particularidad es estar estructurado en torno a la construcción de un personaje. En otras palabras, "el relato construye una vida, inventa un recorrido -recurriendo para ello a una diversidad de materiales y mecanismos- [...]" (Piña, 1989: 136).

No hay duda entonces, que los relatos de vida se pueden narrar y expresar en un discurso oral y mediante estos es posible conocer ciertos aspectos relativos a un entorno, a un suceso o a una época. En este sentido, se están generando testimonios, haciendo hablar a testigos, quienes pueden hacer un relato sobre cuestiones en las que se vieron involucrados de un modo más o menos personal.

Al analizar los testimonios orales hay que tener presente que la narración del pasado ofrecida por un testigo siempre será su verdad, como diría Traverso (2007), una parte del pasado depositada en él. La narración de la experiencia está unida al cuerpo y a la voz, a una presencia "real" del sujeto en la escena del pasado. No hay testimonio sin experiencia, tampoco hay 
experiencia sin narración. En este sentido, la narración inscribe la experiencia en una temporalidad que no es la de su acontecer amenazado desde su mismo comienzo por el paso del tiempo, sino la de su recuerdo, dice Sarlo (2006). En este proceso, la memoria está siempre filtrada por los conocimientos posteriormente adquiridos, por las experiencias que modifican el recuerdo (Piña, 1989: 73 y Sarlo, 2006: 29).

Las notas escritas líneas arriba, son útiles en este texto para mirar desde el presente al sujeto entrevistado, ${ }^{4}$ quien fue testigo y protagonista como alumno de la educación socialista en México, un modelo de instrucción pública que se implementó en las escuelas primarias del país, entre muchas, la escuela primaria Benito Juárez, en la que el entrevistado realizó sus estudios de educación primaria entre los años de 1932 a 1938.

Don Leandro nació el 6 de febrero de 1925 en San Martín Texmelucan, Puebla. Nos relata que en 1938 egresó de la escuela primaria Benito Juárez y asegura que fue "afortunado" porque pudo cursar en dicha escuela desde el primero hasta el sexto grado. En el primer encuentro recordó de manera especial que el año 1938 fue muy significativo para él, porque lo hizo en una escuela destinada únicamente a la educación de las mujeres y él compartió con ellas (Martínez y Padilla, 2007: 63). En plena efervescencia cardenista, la coeducación, formó parte de una de las experiencias educativas más trascendentes de la época.

\section{Escenario de infancia y de los estudios primarios: los años de 1930 en San Martín}

El contexto histórico y social de la infancia de don Leandro y de la escuela en la que realizó sus estudios primarios los ubicamos en la década de los años treinta en San Martín Texmelucan, en el estado de Puebla. De acuerdo a algunos estudios monográficos a nivel estatal como municipal de la época, el municipio de San Martín, como la ciudad del mismo nombre, se localizaban en el distrito de Huejotzingo, en la zona conocida con el nombre de "zona céntrica" del territorio poblano (con una extensión aproximada de 33,995 kilómetros cuadrados), en la que predominan las Ilanuras, "las que prácticamente empiezan por el Occidente en los flancos orientales de la Sierra Nevada y concluyen por el Oriente, en las pendientes occidentales del pico de Orizaba [...] Está dividida en valles secundarios demasiados fértiles y productivos, entre ellos están los de San Martín, Atlixco y Puebla [...]" La

\footnotetext{
${ }^{4}$ El testimonio oral que nos brinda don Leandro quedó registrado en dos entrevistas a profundidad que realizamos en su domicilio en la ciudad de México. La primera entrevista se llevó a cabo el 14 de septiembre de 2003. Cabe mencionar que en ese encuentro nos llamó la atención su interés por relatarnos algunos acontecimientos y vivencias de su infancia, como por ejemplo el haber estudiado su primaria en la escuela Benito Juárez de San Martín Texmelucan, estado de Puebla. De ahí surgió nuestro interés en recuperar junto con él sus experiencias en dicha etapa escolar y con ese fin, siete años después, realizamos una segunda entrevista, el 30 de enero de 2010
} 
zona es productora de cereales con clima templado agradable y constituye la zona industrial del estado, "la que ofrece mayor población absoluta, contando con los mejores medios de comunicación". Por lo mismo, el comercio se consideraba y considera muy activo, en donde anualmente se exportaban principalmente para la ciudad de México grandes cantidades de fruta, harinas, telas, trigo, maíz, chile verde y seco. Junto con los distritos de Puebla, Atlixco y Cholula, "Huejotzingo cuenta con establecimientos fabriles, donde se hilan, tejen y estampan las fibras blandas, principalmente el algodón, el lino, la lana y la seda artificial”, ocupándose en esta actividad buen número de habitantes, unos 9,264, entre ellos el padre de don Leandro, quien trabajaba por esos años en la Fábrica de San Martín, conocida por los lugareños como "El Carmen" (Ponce, 1935: 14-15).

El valle de San Martín asiento de la ciudad y del municipio, fue y sigue siendo demasiado fértil y productor en gran escala del mejor trigo del estado como del país, regado por las arterias formadoras del Atoyac (Ponce, 1935: 190). El municipio de San Martín Texmelucan, con una superficie de 94,44 kilómetros cuadrados, está situado en la parte nororiental del distrito de Huejotzingo, a una altitud de 2,310 metros. En los años treinta del siglo XX, cuando don Leandro estudiaba su primaria, se le consideraba como un municipio agrícola e industrial y se reconocía la fama de sus trigos y chile. Además se llegaba a afirmar que contaba con fábricas de hilados y tejidos de algodón, así como con comercios de consideración, resultando incluso de mayor importancia que Huejotzingo (Ponce, 1935: 190).

La ciudad de San Martín en los años treinta del siglo pasado contaba con una población aproximada de 6,841 habitantes. El comercio, actividad económica de importancia, lo establecían con la capital del estado, la ciudad de Tlaxcala y la ciudad de México, a través de la carretera México-Puebla, el ferrocarril Interoceánico y la carretera aún sin pavimentar por esos años (Ponce, 1935: 190-191).

Durante la década de los cuarenta, San Martín, al igual que otras ciudades del estado y de la república mexicana, experimentó una dinámica de crecimiento de población y expansión urbana en ascenso. Este crecimiento se generó en conjunto con el comercial e industrial; es por ello que a partir de 1960, el municipio, caracterizado por su agricultura, comenzó a transformarse en un lugar industrial y comercial. Un aspecto a destacar es que los gobiernos federal y estatal otorgaron facilidades para el establecimiento de industrias y otras manufacturas.

De acuerdo con los datos estadísticos, en 1930 el municipio de San Martín registraba una población de 19,693 habitantes, que aumentó en 1940 a 21,779 habitantes. El crecimiento demográfico y económico trajo consigo también la demanda de bienes y servicios básicos, entre otros la educación, la salud y la vivienda. Los gobiernos federal y estatal, así como la municipalidad, tuvieron la responsabilidad de su prestación.

Con relación a los servicios de educación o la denominada "instrucción pública", a mediados de la década de los treinta se señalaba a Puebla como una de las entidades que más 
se había preocupado en el país por la instrucción pública y educación de su pueblo, y se anotaba que "gran impulso ha recibido y sigue recibiendo el movimiento educativo en el Estado, la enseñanza día a día recibe nuevas orientaciones abriéndose más vastos horizontes" (Ponce, 1935: 208), reconociéndose que la legislación escolar poblana "destacase en primera línea como una de las más avanzadas del país, va de acuerdo con las tendencias y orientaciones modernas y en más de una ocasión ha servido para inspirar y modelar legislaciones escolares que en otras entidades rigen" (Ponce, 1935: 208). La instrucción pública estaba casi en exclusiva a cargo del Estado, era obligatoria, gratuita y con fines socialistas; "en los diversos planteles existentes se imparten diversas enseñanzas que llenan, dentro de lo posible, las exigencias sociales" (Ponce, 1935: 208). Algunos de estos planteles dependían directamente del gobierno del estado y otros del gobierno de la Federación; "entre los segundos, cuéntese 760 escuelas rurales que están diseminadas por todo el territorio poblano, dos Centros Obreros, uno en Atlixco y otro en la Angelópolis, ambos tienen como fin principal inculcar al elemento obrero las luces del saber" (Ponce, 1935: 208). En total el gobierno federal sostenía un total de 771 planteles educativos, mientras que el gobierno de Puebla tenía abiertas y en servicio unas 260 escuelas, con un personal de 825 maestros para su inspección y "buena marcha" (Ponce, 1935: 209). Los planteles estaban agrupados en cinco zonas escolares. Los distritos de Atlixco, Cholula, Chiautla, Matamoros y Huejotzingo, del cual depende el municipio de San Martín Texmelucan, se incorporaron en la cuarta zona escolar.

Don Leandro estudió la primaria entre los años de 1933 a 1938 y, de acuerdo a datos censales de 1935, la población mayor de diez años en Puebla ascendía a 84,066 habitantes, de los cuales el $29.91 \%$ leían y escribían y un porcentaje mayoritario equivalente a $67.93 \%$ no sabían leer ni escribir. La población infantil menor de 14 años ascendía a 455,649 habitantes. Con relación al escenario local del municipio de San Martín, para esos mismos años se tiene que del total de la población (19,693 habitantes) los alfabetos representaban el 42.99\% (6,029 habitantes), y un porcentaje mayor de 54.48\% (7,639 habitantes) de analfabetas. Aproximándonos a la población entre 10 y 14 años, los porcentajes representaban 54.58\% y 43.90\%, respectivamente. ${ }^{5}$ Estas cifras reflejan el analfabetismo existente tanto en el estado como en el municipio y a fin de enfrentarlo los gobiernos federal y estatal emprendieron la campaña de alfabetización. ${ }^{6}$ El gobierno local de San Martín Texmelucan, como otras po-

\footnotetext{
${ }^{5}$ Los datos estadísticos que aparecen en diferentes fuentes no coinciden en ocasiones. En este caso, apuntamos las cifras del texto de la monografía de Ponce por ser de la época (1935). Sin embargo, se sugiere confrontarlos con los datos que registra Enrique Cordero y Torres en Historia compendiada del estado de Puebla, t. iii, México, Publicaciones del Grupo Literario Bohemia Poblana, 1966, p. 126. Cfr. Quinto Censo de Población, Estado de Puebla, 15 de mayo de 1930, México, edición 1936.

${ }^{6}$ Cabe anotar que la campaña nacional contra el analfabetismo se expidió el 21 de agosto de 1944, siendo secretario de Educación Pública Jaime Torres Bodet, y presidente de la República, el general Manuel Ávila Camacho (Cordero, 1966: 127).
} 
blaciones de la entidad, atendió las necesidades educativas de la población en edad escolar, proporcionando la infraestructura y equipamientos escolares a planteles como en el que estudió don Leandro.

\section{Recuerdos infantiles de la educación socialista}

Las preguntas planteadas al inicio del texto nos aproximan a las percepciones de los protagonistas y testigos de la educación socialista en México, en este texto mediante el análisis de las experiencias y vivencias de los niños durante sus estudios de la primaria. Para efectos de este trabajo, retomamos la entrevista de don Leandro, quien nació en 1925 en la ciudad de San Martín Texmelucan; en su testimonio recuperamos algunos fragmentos de su infancia y vida escolar en la escuela primaria Benito Juárez. En la entrevista nos interesaba saber: ¿Hasta dónde realmente las ideas y el modelo de este tipo de educación trajo consigo cambios en los hábitos escolares? ¿Qué tanto las relaciones entre los géneros y la convivencia social se modificaron? ¿Cómo se recompusieron los espacios y los tiempos escolares, la vida cotidiana escolar en su conjunto? ¿Qué representaron para niños y niñas? ¿Cuál fue la actitud y los comportamientos de los padres de familia y de los maestros ante esta política educativa?

Don Leandro realizó su primaria entre los años de 1933 y 1938 -a decir de él, del primer al sexto curso - en la escuela Benito Juárez, localizada detrás de la Parroquia de San Martín Caballero. Nos aclara que la escuela no siempre estuvo en el mismo terreno: al principio ocupaba una construcción vieja "estilo convento" para después juntarse con la escuela Margarita Maza de Juárez, entre los años de 1935 y 1936, mientras construían el nuevo establecimiento. Recuerda con claridad que el presidente Lázaro Cárdenas llegó a San Martín a inaugurar la escuela, allá por el año de 1939. Llama la atención que en sus primeros recuerdos distingue su paso por la escuela de "parvulitos", y a la pregunta expresa ¿en qué año ingresa a la primaria? responde:

Bueno, exactamente no recuerdo, pero quisiera primero, ya que se trata de eso, hablar de la primaria, porque antes de la primaria tuve una educación preescolar, como se llama ahora. En ese entonces no era kínder, se llamaba escuela de parvulitos [...] Era para los niños de tres a cinco o seis años. Estuve en la escuela esa durante dos o tres años [...] Tuve como maestro un profesor que le decíamos Pachequito y era su esposa o su hija, no me acuerdo, la maestra Tulitas. Estuvimos ahí varios niños y creo que me llevaba mi abuelo, ya que mi padre trabajaba. Estuve, como dije antes, dos o tres años, y al término ingresé a la primaria [...], pero en ese entonces todavía había que entrar a los siete años de edad. 
Menciona que quizá nos llame la atención la palabra "parvulitos", "pero era la palabra que se utilizaba en ese entonces, parvulitos, porque éramos niños de tres a cinco, seis años..."

En 1932, entra al primer año de primaria, como nos relata:

cuando entré a la escuela en primero, segundo y quizá tercero, era presidente de la República el general Lázaro Cárdenas, y no recuerdo si fue en tercero, o en cuarto, cuando se integró lo que en ese entonces se llamó la educación socialista, o sea, integrar los grupos con mujeres y hombres. Allá en San Martín había dos escuelas: una para varones, que está en la parte trasera de la parroquia de San Martín, y una escuela para damas, que está a un costado del convento de San Antonio; el colegio para varones se llamaba Benito Juárez y el colegio para damas se llamaba Margarita Maza de Juárez [...]

En 1934, siendo presidente el general Lázaro Cárdenas, se reformó el artículo tercero constitucional, imprimiendo a la educación un triple carácter: socialista, desfanatizadora y racional. "La Educación que imparta el Estado será socialista y, además de excluir toda doctrina religiosa, combatirá el fanatismo y los prejuicios, para lo cual la escuela organizará sus enseñanzas y actividades en forma que permita crear en la juventud un concepto racional y exacto del universo y de la vida social" (Cordero, 1966: 120).

La reforma educativa arribó a Puebla en 1934, año en el que se registran las campañas que la favorecían, según Enrique Cordero (1966). Acudieron en su apoyo las centrales obreras y las logias masónicas. Otros especialistas en el tema sostienen que los alcances de la reforma en el país fueron diversos y su mayor o menor impacto dependió de las relaciones que el gobierno federal establecía con los gobiernos locales a nivel estatal. En algunos casos dichas relaciones estaban influenciadas por el contexto político que imprimían los grupos de poder local y regional (Vaughan, 1999).

Como lo plantea Mary Kay Vaughan (1999), la implementación del programa de reformas sociales cardenista estuvo determinada por las necesidades políticas del Estado posrevolucionario y su relación con el amplio conjunto de poderes locales y regionales que se formaron antes y después del triunfo revolucionario. Al parecer, el alcance del reformismo cardenista estuvo vinculado a la consolidación de la unidad y el consenso nacional bajo el dominio del nuevo Estado central. Las reformas sociales, como la educación socialista, tenían mayor o menor éxito de acuerdo al acomodo de los poderes locales y regionales en el nuevo equilibrio que construía la familia revolucionaria.

Algo significativo en este proceso fue que el fortalecimiento o debilitamiento de la reforma educativa no dependió del grado de conservadurismo político o del rezago social que

\footnotetext{
7 Segunda entrevista al señor Leandro Padilla realizada en su domicilio, por Concepción Martínez y Antonio Padilla, ciudad de México, 30 de enero de 2010.
} 
se viviera en las regiones, sino de la manera en que los grupos locales de poder lograban acoplarse al equilibrio de poderes que el régimen posrevolucionario requería para su consolidación (Vaughan, 1999: 166-167). En Puebla, por ejemplo, el apoyo político que los sectores oligárquicos proporcionaban al gobierno cardenista en su esfuerzo por fortalecer al Estado central les permitió evitar en sus dominios la intromisión a fondo del régimen durante el impulso a la educación socialista, por lo cual la función de los maestros federales en esa región fue bastante restringida y poco sirvió para transformar radicalmente las relaciones sociales de las comunidades.

Sin embargo, en las escuelas federales las reformas sí se impulsaron, en un contexto de fuertes críticas y agitación social. En el relato de don Leandro esta situación se refiere así:

[...] al integrarse la educación socialista hubo protestas de los padres de familias, pues no concebían que en los grupos hubiera de los dos sexos. Sin embargo, cuando el gobierno se propone algo lo hace. Claro que de momento no se alcanzaban a entender los alcances de la integración de los grupos, pero con el tiempo se ha entendido que fue benéfico, porque si antes no se hablaba de discriminación, por lo menos creo que en ese tiempo fue que empezó a diluirse un poco esa distinción que había entre hombre y mujer... (Padilla, 2010).

Dichas protestas sucedieron desde luego en otras partes del estado, como en la ciudad de Puebla, escenario de múltiples manifestaciones violentas. Como lo menciona Cordero, la escuela socialista fue mayormente repudiada en Puebla por los padres de familia en virtud de los radicalismos que se implantaron: "la educación sexual y la coeducación, la primera sin personal preparado ni conocimientos científicos, a cargo de catedráticos radicales o profesionales facciosos, que cometieron graves errores" (Cordero, 1966: 123).

Al respecto, don Leandro agrega:

[...] el argumento era de que no era posible juntar a las niñas con los niños por el peligro que corrían las niñas, ¿no? [...] Ya desde entonces nos estaban condenando a cosas que ni siquiera nos pasaban por acá, pues éramos niños, teníamos ocho, diez años quizás. ¿Qué pensamientos puede uno tener en ese entonces? Máxime cuando en la casa, en todas las casas, había una restricción en ese asunto [...] En la casa nunca se oía hablar de cosas de sexos como ahora, eso era muy reservado, solamente lo hablaban las personas mayores, y cuando hablaban de alguna cosa de ésas nos echaban fuera, nos echaban para el patio, era un tabú para los niños oír esas cosas, esas pláticas; ése era el argumento que los padres de familia expusieron antes las autoridades.

[...] iban a la escuela, se juntaban cinco, diez, quince padres de familia, veinte, iban ante el director y le exponían que no era posible. No, bueno, pues estas son órdenes del gobierno, son órdenes del presidente, nosotros no podemos hacer nada, más que 
acatar lo que nos manda, y ustedes pues no les queda otra más que acatar también; si quieren que sus hijas se eduquen, tienen que aceptar las cosas [...]

A las preguntas de ¿y cómo los integraron?, y ¿en los mismos grupos habían niños y niñas? Don Leandro responde:

[...] Sí, en los mismos grupos habían niños y niñas [...] Bueno, había bancas, ahí sí nos ponían en unas bancas a las niñas y en otra banca los niños, pero todos recibíamos la misma clase al mismo momento y en los juegos jugábamos todos juntos [...]

Con relación a la actitud de los maestros frente a esta práctica educativa, es importante detenernos en las experiencias y vivencias que recuerda don Leandro de sus maestros. Este aspecto ocupa una buena parte de su relato, quizá por lo significativo que fueron para su infancia:

[...]tuve unos maestros muy responsables, me doy conciencia de ello a partir me imagino que del tercer año de primaria [...] Y hago mención de la actitud de los maestros porque en tercer año tuve un maestro que se llamó Ismael Morales, le decían sus compañeros ave negra. Yo te diría que en ese entonces tendría unos cuarenta años de edad, y me imagino que era de fracción indígena por sus rasgos fisonómicos, era de barba rala y bigote ralo, pero era un maestro muy concienzudo en cuanto a la enseñanza. Era de ideas socialistas porque nos hablaba mucho de -en ese entonces estaba la guerra civil española - y nos hablaba mucho de Rusia, que Rusia apoyaba al entonces presidente Manuel Azaña, que no lo reconocía como presidente el general Franco, y al general Francisco Franco lo apoyaban Alemania e Italia. Entonces prácticamente ahora hago conciencia de que era una guerra no entre españoles sino entre italianos y alemanes contra rusos porque ahí experimentaban sus armamentos que más tarde les servirían para la segunda guerra mundial. El maestro Ismael digo era de tendencias socialistas. En ese entonces la palabra socialismo pues era muy poco usada, se hablaba más bien de comunismo, y a mí la verdad, yo prefiero la palabra socialista a la palabra comunista. Era un maestro muy concienzudo en la enseñanza y quería que no sólo sus alumnos, éramos veinticinco en total, aprendieran, sino que él pidió permiso al director de la escuela para que después de sus horas de trabajo, que terminaban a las cinco de la tarde, hiciera un curso especial para gente del pueblo, para la población y en especial para los obreros. Hasta la actualidad hay dos fábricas textiles, una que se conoce como "El Carmen" pero la razón social es Fábricas de San Martín y la otra, "El Pilar", él quería que los trabajadores aprendieran también, porque la mayor parte de los trabajadores no sabían leer ni escribir y el director le concedió el permiso para que hiciera por su cuenta y riesgo ese turno nocturno para los trabajadores y la población en general que quisiera ir. Pues sí, despertó interés porque según recuerdo, aproximadamente había unos cuarenta o cincuenta alumnos ya todos 
mayores de edad, había también mujeres porque pienso que siempre la mujer ha tratado de superarse, aun en esa época en que la mujer estaba muy sujeta a las tradiciones familiares.

Este fragmento de testimonio revela la imagen del maestro que don Leandro conserva en su imaginario y que en cierta forma coincide con la imagen que los preceptores de la educación socialista defendían y trataban de llevar a la práctica (Vaughan, 1999; Cordero, 1966; Cruz, 1995)

De acuerdo con los argumentos del maestro Jesús de la Rosa, uno de los profesores de la época y defensor de los principios de la educación socialista, el maestro dejó de ser expositor de conocimientos generalmente sin interés para el alumno, con personalidad y trabajo importante, y se consideraba sobre todo un agitador y orientador social: un participante activo en la vida de la comunidad. Dice el maestro De la Rosa que la profesión de maestro:

"se viriliza", sube su importancia, su papel [...], hasta su actitud e indumentaria cambian por completo. Será un maestro "obrero" a medida que adquiera preparación intelectual y manual para realizar eficientemente la tarea de transformación de nuestros regímenes social, económico y político [...] La maestra tiene una importancia no menor al maestro, será una guía, una orientadora del hogar, toda una técnica en el trabajo de la escuela [...] (De la Rosa, 1985: 133).

Don Leandro prosigue su relato, recordando:

Ese maestro [Ismael Morales] lo recuerdo con cariño porque independientemente de que era muy enérgico en su enseñanza también era muy noble. A mi padre lo quiso mucho y le ofreció inclusive hacerlo maestro rural; le dijo que si quería él lo podía proponer para maestro rural, cosa que mi padre, no sé por qué, no aceptó. Mi padre era de las pocas personas que sabía un poco más de leer y escribir y el maestro lo apreciaba mucho por su cualidad para aprender [...] A mí me decía cuando lo hacía enojar, que era muy frecuente, me decía: mira Leandrito, tú serás muy inteligente, eres muy listo, pero a tu padre no le llegas ni a los talones. Eso me daba una idea del aprecio que sentía por mi padre y el reconocimiento que le hacía porque a pesar de su escasa educación pues era una persona que sabía discernir las cosas y resolver los problemas [...]

Ante las preguntas ¿qué les decía su maestro cuando les hablaba de historia, de geografía? y ¿cómo se reflejaba la ideología del maestro?, don Leandro respondió:

Su ideología de maestro, digo la ideología socialista que él tenía, nos la manifestaba cuando era la clase de civismo. Había una materia que se llamaba civismo, ahí era donde nos decía, y también en historia. En la de historia nos decía especialmente del 
armamento que tenían los rusos, los armamentos que tenían los alemanes y los italianos; y nos hablaba mucho de Rusia, decía que era un país muy grande, muy poderoso y que sus aviones eran invencibles porque según las alas tenían unas [...] como rejillas para que pasaran por ahí las balas y yo pues [...] me imaginaba cuando nos decía que era un país muy grande, muy poderoso, muy hermoso y muy bonito que sus ciudades eran muy hermosas, me hacía yo a la idea: bueno, conocer un país de esos ¿cuándo?, nunca jamás. Recuerdo con cariño a otros profesores, de cuarto año, de quinto año, en especial a todos mi reconocimiento porque eran unos maestros en verdad amantes de su profesión, amantes de su carrera, [...] eran muy estrictos con ellos mismos. En una ocasión el gobierno del estado no tenía dinero para pagarles a los maestros su sueldo y pasaron creo que dos meses sin recibir sueldo. ¿De qué vivían los maestros?, pues los padres de familia reconocían su esfuerzo y su dedicación a la enseñanza de los niños, a pesar de que no les pagaban, jamás, jamás dejaron de dar una clase y es ahí donde mi reconocimiento es mayor y hago una comparación actual, que los maestros por cualquier cosa hacen un paro y son irresponsables [...]

A la pregunta ¿se acuerda cómo se llamaba el director de la escuela?, relata:

[...] Sí, Héctor Manuel, se me fue el apellido. Era un maestro muy enérgico también, digo, todos los maestros eran enérgicos, pero había un cierto grado de suavidad en el trato con los alumnos, aunque eso no quiere decir que cuando cometíamos algún desmán no nos corrigieran, porque además pues entonces los niños no teníamos ningún derecho, el único derecho que teníamos era recibir educación y educación doble, porque por un lado en la casa había rectitud y por otro también en la escuela había rectitud, porque los padres le decían al maestro: maestro, si las orejas de mi hijo me entregan se las recibo. Ahora no, ahora ya los niños tienen tantos derechos, que pues los maestros no se atreven a tocarlos por miedo a que tenga problemas con los padres y con las autoridades correspondientes, inclusive hasta demandan, creo que demandas ha habido casos...

Con relación a los horarios escolares, don Leandro relata:

en esa época de mi enseñanza primaria se iba en la mañana y en la tarde a la escuela, se entraba a las nueve de la mañana y se salía a las doce del día a comer y regresábamos a las tres y salíamos a las cinco, el maestro se tomaba una media hora de descanso y los alumnos de la nocturna, que eran las gentes mayores, entraban a las cinco y media y salían a las ocho.

De acuerdo a la doctrina de la educación socialista que se impartiría en la escuela primaria se señalaba que debería ser "progresiva, funcional y activa" (Guevara, 1985: 106-108), es decir, que abogaba por una enseñanza inspirada de acuerdo a las necesidades orientadas a 
su satisfacción, y en donde los alumnos aprendieran las cosas haciéndolas, para que fueran ellos mismos, dirigidos por sus maestros, los agentes de su propia educación. En este sentido, las autoridades escolares formularon programas para las diversas asignaturas a través de las cuales quedaran incluidos los conocimientos científicos, éticos y estéticos, las enseñanzas manuales y las actividades sociales. El plan de trabajo quedó integrado por estudios y actividades de lengua nacional, cálculo aritmético y geométrico, observación y estudio de la naturaleza, ciencias sociales, enseñanzas manuales y economía doméstica, actividades artísticas y educación física (Guevara, 1985: 113, 143-144).

En el caso de las materias que cursó don Leandro en la escuela Benito Juárez y ante la pregunta ¿qué era lo que le enseñaban?, recuerda:

[...] Bueno, las materias básicas siempre han sido aritmética, geometría, geografía, historia, ciencias físicas y naturales, lengua nacional, lectura, dibujo, artes manuales. Creo que siguen siendo las mismas materias ahora pero las han cambiado de nombre, pero en ese entonces era así y era no sólo la clase oral, sino que pasábamos al pizarrón y además hacíamos un resumen por escrito de lo que habíamos aprendido y eso nos ponían de tarea cuando terminábamos del curso diario, nos ponían de tarea repasar. Yo la verdad pocas veces recurría a los resúmenes que escribíamos, no porque me quiera yo dar de muy este inteligente y que tuviera yo mucha retentiva, pero sí tenía yo poder de retención y la mayor parte de las cosas se me quedaban grabadas.

Con relación a los exámenes agrega:

[eran] pruebas que nos hacían de conocimiento de lo que nos habían enseñado, nos ponían problemas de aritmética, problemas de geometría. Nos enseñaban en geometría a trazar figuras geométricas, nos ponían a hacer fórmulas que desgraciadamente ya se me han olvidado con el tiempo, pues han transcurrido sesenta y tantos años, ¡no, qué!, más de sesenta años han transcurrido, así es de que pues ya ahorita difícilmente me podría yo hacer una, por ejemplo, una cuadriculación de un terreno [...]

En este testimonio también encontramos expresados los recuerdos de diversos materiales escolares, entre otros, libros, pizarrines, tizas. Con relación a este aspecto y como lo menciona Vaughan (1999), al igual que los programas escolares y contenido de las asignaturas, también se registraron cambios en los contenidos de los libros de texto. Señala esta autora que las obras empleadas para formar a los estudiantes también se diseñaron de acuerdo al tipo de pedagogía que pondría en práctica el Estado en cada momento y también vivieron en cierta forma una radicalización pedagógica en su contenido entre los años veinte y los treinta, ya que fue muy claro el desplazamiento de los contenidos cívicos liberales por los temas de corte populista. Como menciona: 
en los textos de la reforma educativa socialista, para los cuales la revolución seguía su marcha, Zapata se convirtió en un héroe singular. Desde el pasado lejano surgió José María Morelos como campeón de la independencia nacional, la democracia popular, la reforma agraria y hasta los derechos de los trabajadores. Comenzaron a aparecer en los libros las primeras historias de la organización de los trabajadores durante el porfiriato. Se hacía hincapié en la unidad del obrero y el campesino en su lucha, aunque ésta no siempre constituyó una realidad durante los años del conflicto armado... (Vaughan, 1999: 94-95).

Además, los textos engrandecían el papel del trabajo en la producción de bienes y servicios para la sociedad, y también "procuraban convertir al obrero y al campesino en agentes de su propia historia. Describían formas específicas de acción: organizar cooperativas de producción y consumo, y administrarlas a diario por medio de comisiones de vigilancia y consejos de administración; llevar a cabo reuniones sindicales y organizar huelgas; introducir cultivos y herramientas nuevos". En fin, "deseaban crear en el aula estas lecciones de esfuerzo colectivo" (Vaughan, 1999: 95-96).

En 1934, la Comisión Editora Popular de la Secretaría de Educación Pública emprendió la tarea de publicar libros de texto y de lectura y distribuirlos gratuitamente o a muy bajo costo a los niños y alumnos adultos de la nación, como lo señala Vaughan (Vaughan, 1999: 91). Con relación a este punto, don Leandro relata:

[...] ah, y quisiera hacer mención también que los primeros años en primero y segundo no se usaban cuadernos, se usaba un cuadrito de pizarra que se llamaba la pizarra y se escribía con un pizarrín, era el complemento para escribir y tenía uno que memorizar, porque como se borraba para hacer otras clases de actividades, se tenía que memorizar para borrar y volver a utilizar la pizarra en otros temas. Ya en tercer año, sí, ya empezamos a usar libros, cuadernos. Ya nos daban nuestra lista de útiles a principio de año, se iba a surtir a una tlapalería que era de los señores Contreras, don Luis Contreras Martínez, ahí casi todo el mundo se surtía, aunque había otras dos tlapalerías más que también expendían artículos escolares, pero esa era la que tenía más demanda y ahí era donde mis padres me compraban mis cuadernos, mis útiles. Había un libro que en ese entonces que era el digamos de lectura obligada se llamaba Libro México. Me acuerdo que ese libro lo cursamos en diferentes grados desde luego, primero, este, tercero, cuarto, creo que hasta el quinto año tuvimos todo ese libro, diferentes grados, ¿no?, diferentes tipos ya de lecturas [...]

Los hábitos y prácticas escolares se conjugaron con los espacios y tiempos de los juegos infantiles. En el caso de don Leandro, es muy significativa la remembranza del juego en el columpio que existía en el jardín de la escuela y lo que tuvo que hacer para poder acceder a éste.

En su plática relata que una vez le habían dado las llaves de la escuela: 
[...] eso fue también alrededor del tercer año, porque en ese entonces mi padre se había casado y vivíamos, vivía yo con él, fue de las pocas veces que tuve la ocasión de decir que vivía en un hogar. La señora, la recuerdo con mucho cariño porque no fue la clásica madrastra que de la que se habla y la que se dice tantas cosas... Para ella, yo fui el hijo que hasta ese momento todavía no tenía con mi padre, y me quería tanto, de veras, que contra lo que estaba yo acostumbrado me hacía que me bañara dos o tres veces a la semana y me cambiaba de ropa también dos o tres veces a la semana. El maestro Morales había hecho un criadero de conejos, y a mi padre le encantaba comer conejo, entonces le decía el maestro: el que me traiga un quintal de alfalfa se lleva un conejo, entonces le decía yo a mi padre fíjate que el maestro dice que si le llevamos un quintal de alfalfa para los conejos nos da uno, "pues cómprala y llévasela y que te dé el conejo"... Lo guisaba Dominga, mi madrastra, [...] y nos dábamos un banquete en ese día. Me tenían tanta confianza que me dieron las llaves de la escuela para abrir, y la verdad casi puedo decir que lo busqué porque no se hacen las cosas nada más porque sí, sino porque todavía era en la escuela vieja, en la Benito Juárez, había un árbol muy frondoso y había una rama que estaba colgando, pero una rama fuerte, hicimos un columpio ahí y ese era mi deseo, yo poder mecerme sin que nadie me lo fuera a impedir, y a eso se debió quizás mi empeño en portarme bien, en llegar temprano a la escuela. De por sí siempre Dominga procuraba que llegara yo siempre a la escuela, me daba de desayunar temprano, me obligaba a asearme, mi mochila y me iba yo a la escuela, entonces por eso creo que el maestro se fijó en mí, dice: "te voy a dar las llaves para que tu abras, te encargues de abrir". Entonces de entrada eran las nueve, yo llegaba ocho, ocho y cuarto, ocho y media para que ese tiempo gozara yo del columpio [...] Yo abría, yo tenía las llaves y a las diez para las nueve abría la escuela; ya me había yo hastiado o regocijado con el columpio y ya estaba yo contento, feliz, tranquilo de que me había divertido yo solo.

Don Leandro relata que en 1937 terminó el quinto año en la escuela Benito Juárez que era de varones y para ese año integrada con mujeres. En 1938 cuando iba a pasar a sexto año, el presidente Cárdenas ya había mandado a derruir dicha escuela, razón por la cual en este año concluyó la primaria en la nueva escuela Margarita Maza de Juárez. De acuerdo a su recuerdo y a su percepción, la construcción llevó dos años y constituía una escuela adecuada a las necesidades en ese entonces de la población estudiantil, una escuela bien integrada, bien hecha y con maestros supuestamente mejor preparados. Menciona que hasta la fecha existe incluso en su fachada una placa en la que está inscrita la fecha de su inauguración, en el año de 1938.

El año de 1938 se conserva en la memoria de don Leandro porque es el año que marca dos hechos importantes de su infancia: el término de su primaria y la inauguración del "nuevo" establecimiento escolar. 
Al término de su primaria, don Leandro recuerda los caminos que siguieron sus compañeros de escuela, incluso las rutas que emprendió al término de su educación primaria. Nos interesa destacar, por ejemplo, las remembranzas de sus compañeros de aulas y de sus estudios y actividades posteriores:

[...] ya desde entonces había la inquietud de querer estudiar más, pero no había posibilidades porque no existía más que esas dos escuelas y una academia de taquigrafía y mecanografía, pero era de paga, no era pública. Algunos de mis compañeros, los inscribieron allí y aprendieron la carrera de mecanografía y taquigrafía, pero la mayor parte nos quedamos ya sin poder estudiar. Algunos compañeros tuvieron la fortuna de que sus familiares tenían mejores posibilidades, y Miguel Ángel Rodríguez -le decíamos Angelín- estudió para sacerdote... Supe con el tiempo, con los años, ya cuando vivió aquí en México, que era sacerdote de una iglesia en Tlatelolco. Me hice alguna vez la intención de ir a visitarlo pero la verdad no pasó de ahí. Otro compañero tuvo la fortuna que su hermanastro lo mandara a estudiar a México y a él sí me lo encontré aquí dos o tres veces en México y estudió para anestesiólogo, y otros compañeros que se fueron para Puebla, allá cambiaron su modo de vivir quizá estudiaron también, ya perdí contacto con ellos. Pero sí recuerdo mucho a algunos de ellos porque la llevé bien con ellos. A pesar de que eran un poco mayores que yo, la llevé bien con ellos. Unos hermanos Dueñas, Vicente y Luis Dueñas, que habían llegado a San Martín de Torreón, Coahuila, de una fábrica textil que había allá y a su papá lo contrataron en la fábrica del Pilar y llegaron allá y se inscribieron en la escuela y estuvimos dos o tres años juntos. Recuerdo también con cariño y afecto a otro compañero, Teófilo Soto, que parece que actualmente todavía vive, es un poco mayor que yo, dos o tres años, es de una de las familias distinguidas allá en San Martín, el papá de él era [...] les Ilamaban "tenedores de libros", me imagino que era auxiliar de contador o algo así, pero su profesión era eso, y tenía varios hermanos. Me acuerdo de Severo, de Cuco de Teófilo, de sus hermanas y otro hermano más chico, no me acuerdo el nombre ahorita, pero fueron compañeros con los que tuve muy buenas relaciones, especialmente con Teófilo.

Los nombres de sus compañeras también llegan a sus recuerdos. Al respecto, menciona:

Esperanza Salazar, que era familiar creo que de los dueños administradores de la hacienda que se llama Polastra, cerca de San Martín. Otra muchacha era hija de un señor que tenía una farmacia: Humberto Meldraña, y otra muchacha, Alicia Álvarez, era su padre el conductor de ganado, y dos muchachas eran rancheras: las hermanas Osorio, Guadalupe y María Luisa Osorio [...] No, María Luisa y Agustín Osorio, y otra compañera, Guadalupe de la Rosa, eran el mismo número desde que llegamos a tercer año hasta que salimos [...] 
A la pregunta ¿usted se llevaba bien con ellas?, don Leandro responde: "sí, no había [...] mayor problema". Por otra parte, en el testimonio se refleja otro aspecto importante: la heterogeneidad social que imperaba en las escuelas primarias "socialistas" como en las que estudió el protagonista de este trabajo. De acuerdo al relato, encontramos hijos de familias de obreros, artesanos, técnicos, comerciantes, rancheros. Con ello se cumple con una de las características que apuntaban fuentes documentales de la época de "una escuela primaria socialista": una escuela primaria mexicana, porque procura unificar cultural, lingüística y étnicamente a los heterogéneos grupos sociales que integran nuestra población (De la Rosa, 1935: 123).

El relato de vida de Don Leandro termina afirmando: "En fin, esa fue mi vida escolar".

\section{Un epílogo}

Don Leandro no prosiguió sus estudios secundarios. Alrededor de los 16 años emprendió otros aprendizajes y otras prácticas culturales informales al incursionar en el mundo fabril, cuando a instancias de su padre ingresó a laborar en una de las fábricas textiles de San Martín como aprendiz de tejedor, oficio que heredaría de su progenitor. Tiempo después, fue convocado al servicio militar nacional como conscripto, lo que lo llevó a la ciudad de México. Una vez concluido su servicio militar y con las experiencias culturales formales e informales en su haber, comienza a trabajar en una de las empresas textileras más importantes de la capital del país, La Fama Montañesa, en los años cuarenta. Como don Leandro evoca y reconoce, su paso por la escuela primaria fue decisivo para configurar su itinerario y valorar la importancia de la experiencia educativa, social y cultural que representó la educación socialista.

\section{Fuentes}

Altamirano, Graziella (1994), "Metodología y práctica de la entrevista", en Graciela de Garay (coord.), Historia con micrófono, México, Instituto Mora, pp. 62-78.

Bertely, María (2005), "¿Apropiación escolar o etnogénesis? La escuela federal y socialista en una villa zapoteca mexicana (1928-1940)", Memoria, conocimiento y utopía. Anuario de la Sociedad Mexicana de Historia de la Educación, núm. 1, enero 2004-mayo 2005, pp. 39-62.

Civera, Alicia (1999), "Crisis política y reforma educativa: el Estado de México, 1934-1940", en Susana Quintanilla y Mary Kay Vaughan (eds.), Escuela y sociedad en el periodo cardenista, México, Fondo de Cultura Económica, pp. 141-165.

(2006), "La coeducación en la formación de maestros rurales en México (1934-1944)", Revista Mexicana de Investigación Educativa, vol. 11, núm. 28, pp. 269-291.

Collado, Carmen (1994), "¿Qué es la historia oral?", en Graciela de Garay (coord.), La historia con micrófono, México, Instituto Mora, pp. 13-32. 
Cordero y Torres, Enrique (1966), Historia Compendiada del Estado de Puebla, t. III, México, Publicaciones del Grupo Literario "Bohemia Poblana".

Cruz, Salvador (1995), Historia de la Educación Pública en Puebla 1790-1982, t. II, México, Benemérita Universidad Autónoma de Puebla.

Cueva, María de Lourdes (1990), "Construyendo la educación socialista. Gobierno y maestros en Sinaloa (1935)", Arataia, núm. 2, pp. 33-39.

De la Rosa, Jesús (1985), "Características de la escuela socialista mexicana”, en Gilberto Guevara (comp.), La educación socialista en México (1934-1945), México, El Caballito Ediciones.

Marínez, María del Rosario (2005), La escuela primaria en el territorio norte de Baja California durante el régimen del presidente Lázaro Cárdenas, 1934-1940, México, Universidad Autónoma de Baja California.

Martínez, M ${ }^{a}$ Concepción y Antonio Padilla (2007), "Itinerarios, espacios y prácticas de la cultura obrera en México, en la segunda mitad del siglo Xx", en Mario Camarena, Historia oral de los procesos sociales del siglo XX, México, Dirección de Estudios Históricos/INAH, pp. 59-84.

México (Estados Unidos Mexicanos) (1930), Quinto Censo de Población. Estado de Puebla. 15 de mayo de 1930, Dirección General de Estadística/Secretaría de la Economía Nacional, México, [documento pdf disponible en: <http://www.inegi.org.mx/prod_serv/contenidos/espanol/bvinegi/productos/ censos/poblacion/1930/pue/QCPEPUE30I.pdf> (consulta: 23/3/2015)]

Montes de Oca, Elvia (2002), "Las maestras socialistas en el Estado de México, 1934-1940", Sociológica, vol. 17, núm. 48, pp. 185-212.

(2007), "La educación en México. Los libros oficiales de lectura editados durante el gobierno de Lázaro Cárdenas, 1934-1940”, Perfiles Educativos, vol. 29, núm. 117, pp. 111-130.

Padilla, Antonio (2010), "Atmósferas y escenarios de la vida educativa", en Horacio Crespo, Historia de Morelos. Tierra, gente, tiempos del Sur, Colección Política y Sociedad en el Morelos posrevolucionario y contemporáneo, Gobierno del Estado de Morelos, UAEM, Ayuntamiento de Cuernavaca, Instituto de Cultura de Morelos, pp. 253-275.

Padilla, Yolanda y Salvador Camacho (1997), "La resistencia a la educación socialista en Aguascalientes", Educación, núm. 30, pp. 46-49.

Palacios, Mario (2011), "La oposición a la educación socialista durante el cardenismo (1934-1940): el caso de Toluca", Revista Mexicana de Investigación Educativa, vol. 16, núm. 48, enero-marzo, pp. 43-71.

Piña, Carlos (1989), "Sobre la naturaleza del discurso autobiográfico", Argumentos, núm. 7, agosto, pp. $131-160$.

Ponce, Guillermo (1935), Monografía Poblana. Breve reseña geográfica del Estado de Puebla, México, Imprenta La Mercantil.

Quintanilla, Susana (1999), "El debate intelectual acerca de la educación socialista", en Susana Quintanilla y Mary Kay Vaughan (eds.), Escuela y sociedad en el periodo cardenista, México, Fondo de Cultura Económica, pp. 47-75.

Rockwell, Elsie (1999), "Reforma constitucional y controversias locales: la educación socialista en Tlaxcala, 1935-1936", en Susana Quintanilla y Mary Kay Vaughan, Escuela y sociedad en el periodo cardenista, México, Fondo de Cultura Económica, pp. 196-228.

Sarlo, Beatriz (2006), Tiempo Pasado. Cultura de la memoria y giro subjetivo. Una discusión, Buenos Aires, Siglo XXI.

Traverso, Enzo (2007), "Historia y Memoria. Notas sobre un debate", en Marina Franco y Florencia Levin, (comp), Historia reciente. Perspectivas y desafíos para un campo en construcción, Buenos Aires, Siglo XXI.

Valdés, María Candelaria (1999), "Educación socialista y reparto agrario en La Laguna" en Susana Quintanilla y Mary Kay Vaughan (eds.), Escuela y sociedad en el periodo cardenista, México, Fondo de Cultura Económica, pp. 229-250. 
Vaughan, Mary Kay (1999), "El papel político de los maestros federales durante la época de Cárdenas: Sonora y Puebla", en Susana Quintanilla y Mary Kay Vaughan (eds.), Escuela y sociedad en el periodo cardenista, México, Fondo de Cultura Económica, pp. 166-195.

(2000), La política cultural en la Revolución: maestros, campesinos y escuelas en México 1930-1940, México, Fondo de Cultura Económica-Secretaría de Educación Pública.

Vázquez, Josefina (2000), Nacionalismo y educación en México, México, El Colegio de México.

María Concepción Martínez Omaña. Investigadora del Instituto de Investigaciones Dr. José María Luis Mora. Doctora en Sociología. Líneas de investigación: Política, gestión y cultura del agua. Siglo xx; Representaciones y prácticas de la infancia. Siglo XX; Política Pública y transformaciones urbano-regionales. Siglo Xx. Publicaciones recientes: (2013) "Y no tanto que el lugar nos pertenezca, sino que nosotros le pertenecemos al lugar", en Gerardo Necoechea y Patricia Pensado (coord.), El siglo XX que deseábamos. Ensayos de historia oral en torno a experiencia y expectativa, México, Instituto Nacional de Antropología e Historia, pp. 175-201; (2012), "Actores de la Educación Especial en México. Representaciones y prácticas sociales en la segunda mitad del siglo xx", en Antonio Padilla (coord.), Arquetipos, memorias y narrativas en el espejo. Infancia anormal y educación especial en los siglos XIx y xx, México, Juan Pablos editores y Universidad Autónoma del Estado de Morelos, pp. 269-306.

Recibido: 15 de mayo de 2014

Aceptado: 20 de octubre de 2014 